\title{
Intervention Support for Children who Experience Mathematics Difficulties in Grade 3
}

\author{
Maphetla M Machaba
}

\author{
Department of Early Childhood development, University of South Africa, \\ P.O.Box 392 Preller Street, Muckleneuk, 0003 \\ machabmm@unisa.ac.za
}

\author{
Doi:10.5901/mjss.2014.v5n20p1652
}

\begin{abstract}
The South African government's policy that all children should be taught because as it is an important and necessary life skill that cannot be done without. However many teachers are still finding it difficult to teach children to solve mathematical problems. performance is a universal outcry in South Africa. Children as early as foundation phase are unable to solve mathematical difficulties. In her analysis Naledi Pandor noted in that only $35 \%$ of children in South Africa can read, write and count. According to the Global Competitiveness Survey of the World Economic Forum out of 131 surveyed countries South Africa was ranked 128 for the quality of its and science education. Between 1998 and 2005 education in South Africa education improved quantitatively and not qualitatively in comparison with other developing countries. The trends in International \& Science study in 2003, shows South Africa at the bottom pile of 46 participating countries. It was even lower than Ghana, Saudi Arabia and Botswana to mention but few. The South African children achieved significantly poorer results than all other participating countries, including Morocco and Tunisia, and were (on average) older than all other children. Using the qualitative approach, the study will explore designing a model for Foundation Phase teachers in supporting children who experience mathematical difficulties, and then to investigate the factors that contribute to mathematics problems in Foundation Phase children and to determine intervention strategies are in place in supporting children who experience mathematics difficulties. Five teachers will be interviewed, observed and the documents will also be collected.
\end{abstract}

\section{Introduction}

There has been a growing recognition of the importance of the early years for the acquisition of mathematical skills in South Africa. The realisation that a strong foundation is needed if children are to be successful in learning at higher grades prompted the Department of Basic Education (DBE) to conduct systematic evaluations in mathematic competency at primary schools. Although the poor outcome of the Annual Assessment (DBE 2012) was symptomatic of dissatisfactory performance levels in the Foundation Phase research at this level remains scant indicated good mathematical skills later in the school in numerous studies (Department of Basic Education, January 4 (2012:3).

\section{Literature Review}

The aim of our research is to establish the approaches teachers use when teaching computations in , to establish other difficulties teachers experience when teaching computations, to establish which aspect of that is most problematic and also to establish how teachers resolve the problem with the aim of developing a support programme for Foundation Phase teachers.

Croark, Mehaffie \& Greenberg (2007:3) and Joiner (1978:4) have clearly documented that the early identification of children who experience difficulties to learning is of critical importance in enabling such youngsters not only to make greater progress but to become participating members of society. It is important to identify children who experience difficulties to learning as early as possible so that services can minimise or eliminate learning difficulties. On the other hand, it is important to avoid placing harmful labels on young children that lead to lower expectations for achievement. If children who experience difficulties to learning can be identified during early childhood development, they stand a better chance of success since the problem can be addressed.

Steele (2004:75) further supports the notion that early identification of learning difficulties provides a foundation for later learning and academic success experiences for children at risk. He also claims that if children who experienced difficulties to learning are identified in the early childhood years, it is much more likely that they will have the opportunity to develop to their true potential. Early identification also prevents secondary difficulties from occurring and children who are identified early will have a greater chance of not developing secondary difficulties, such as frustration and anxiety. 
Early intervention implies some socio-economic benefits in that prevention or early treatment of developmental problems in young children may reduce more serious, burdensome difficulties with which society may need to cope later, including the accompanying costs.

If children who experience difficulties to learning are not identified early, the learning difficulties continue, which could lead to children dropping out of school, exhibiting behavioural problems and developing greater academic deficiencies.

In addition, early identification of learning difficulties will improve educational opportunities and outcomes for all children with complex needs or particular types or patterns of difficulty in learning in the ordinary school system. Even though every day teachers are faced with children who fail or drop out of school, this does not mean that these children are not capable of doing anything.

Possibly these children might not be able to see well, or may have hearing problems, or handwriting difficulties. For example, children with handwriting difficulties may experience difficulty in keeping up with copying, especially when viewing the material from a distance (such as when they are copying from the chalkboard). They may also experience difficulty in spatial organisation when writing or copying. The child's writing of words or numbers on a page may go upward or downward, or may be cramped too close together or spread too far apart. The child's letters or numbers may appear distorted or rotated (Guerin, 2006:45 and Pierangelo, 1994:74).

\section{An Early Intervention Strategy in Literature and Programme}

In 1997, the Scottish Office of Education [Intervention] Department (SOEID) decided to implement an early intervention strategy in literature and as part of a national programme to raise standards in the early stages of primary education in Scotland. This strategy targeted P1 to P3 stages and children from five to seven years old (Stobie, 2004:157). It is a prevention programme.

The programme involved in-service training and staff development on literacy and for P1 teachers. It emphasised the teaching of phonological awareness through concentrating on the first phoneme in a word and the remainder of the words, a book-rich environment and parent involvement. It also concentrated on a staff tutor to work with the schools involved in the programme and to lend support to teachers in improving approaches to literacy and. The programme also had to have qualified nursery nurses who had to work collaboratively in P1 classes in the schools. A lending and evaluation collection of resources for and literacy for schools is also involved in early intervention. Finally, there is provision of more resources for book corners for P1, P2 and P3 levels (Stobie, 2004:158).

The one dimension of this programme concerns populations who are about to undergo life transitions like entering school and who lack positive early learning experiences. These populations also lack positive early learning experiences and find school to be a challenging process in which they may meet failure (Stobie, 2004:158).

It is these kinds of children, on which the study concentrated. They stem from a "retarded" milieu, are poverty stricken and, most if not, all of them did not attend nursery school and thus they come to school with no prior experience of formal learning. Hence, school is viewed by these children as a place where they are likely to fail and consequently they enter school without any motivation. These children also lack experience (prior knowledge is retarded) in that they come from a poor environment, where for example, parents are illiterate, there are no books, television and newspapers to stimulate them.

The aim of the programme was to identify aspects of programme delivery in the selected schools that had to do with good practice in connection with and literacy. Case-study methodology was used to examine the following variables:

- the use of staffing - including nursery nurses

- approaches to curriculum - including environment and parent engagement

- introduction of phonic sounds - recording children, and

- Parents' perspectives (Stobie, 2004:159).

The analysis included samples of documentation (school policies on early intervention, school development plans, etc.), class observation of interactions between children and teachers (nurse included), interviews with principals, class teachers, nursery nurses, class assistants, parents to children, and children and a questionnaire regarding literacy administered to the children involved (Stobie, 2004:159).

This analysis strategy is similar to the one used in this study even though the SOEID programme goes a little further than the one used in this study by involving the principals and nurses.

The findings reflected the importance of the increased staffing by nurses. The nurses and classroom assistants were considered as an important part of the programme. Their function was to strengthen teaching and to foster the 
children's interest in literacy and activities. They also successfully planned and recorded and assisted in identifying children at risk of failure.

Observation revealed that children in the first two years of study, where additional staffing was routinely used to create smaller teaching groups, were very responsive and engaged in their learning. Interviews with class teachers and principals showed that staff development opportunities were highly valued and that there was a continued need for ongoing staff development with regard to and literacy, especially classroom management and organisation together with planning and target setting. In-service training was regarded as very important, especially for new staff (Stobie, 2004:160).

In other words, this programme highlighted the fact that all staff members should work together in order to ensure the success of the programme. This is lacking in the schools in this study, where grade teachers seem to be on their own and intervention is only done at certain times for specific identified children, instead of there being an ongoing preventative strategy. The main disadvantage of this strategy was found to be a lack of staff to sustain the programme.

The teachers agreed that there was an increase in the levels of achievement as a result of an increase in the pace of children learning. This could also be attributed to staff development in the theoretical background of the strategy. This improvement was better recognised where there was a high degree of record-keeping and target setting (Stobie, 2004:161).

In the schools that participated in this research, the above mentioned were found to be lacking. It is vital that attention should be paid to these aspects of the strategy. Without proper record-keeping and target setting, progress will be slow. In some schools, children who experience difficulties are identified each year by class teachers instead of them being identified once and a record kept of their development through the various stages and targets set for them to achieve. In the schools in this research, the identification of children and the remedial work involved occurs on an ad hoc basis and does not lead to a permanent solution.

The focus group interviews and questionnaires indicated that parent involvement in classrooms and home support to children was uneven in the phases (grades). The study revealed that Grade 3 children received little help with reading and at home. The Grade 3 children also used the book corners in the classrooms (Stobie, 2004:161). Despite this, parental involvement was evident in participating schools. Home-school diaries were used and interviews with parents confirmed that these workshops helped parents to help their children at home.

However, some parents were not clear how to assist the children with numbers. Parental support seemed to decrease in Grade 3 compared to earlier grades (Stobie, 2004:162). Although parent involvement was low, it was better than that at the schools under investigation. This indicates that parents need to be encouraged to play a more active role in their children's education, especially at the lower grades, to render the child's transition to formal education easier.

The provision and use of resources, human and material, is important for the success of the programme. Initial and continued training for staff is needed for the success of the programme. Assessment needs to be built into the programme as well. The result of assessments, especially national assessments, should be fed back to the schools (Stobie, 2004:166). Doing this would ensure success.

This programme relies on all the role players pulling their weight in order to achieve success. The role of the teacher and the other staff is critical, for it is at this level of the programme that identification and remedial work is conducted. If properly carried out, the programme can go a long way in helping children. This kind of intervention, if adopted in South Africa, could contribute greatly to helping to remedy the problems encountered in South Africa. The programme was also applied among children from a poor economic background as prevailed in the schools where the researcher conducted this research.

\subsection{Research methodology}

The qualitative approach was used in this study to explore the views of Grade 3 teachers regarding the approaches they use in teaching and learning of computation. We opted for this approach as it allows researchers to gain insight into the inner experience of participants, to determine how meanings are formed through culture, and to discover rather than test variables (White 2005:81 and Corbin \& Strauss 2008:12). To collect data we used semi- structured interview as it helped to explain in detail what approaches teachers use when they teach computations in . For the purpose of this paper, we interviewed and observed five teachers from five different schools. The interviews were held during school time and lasted approximately 1-1 and half minutes. We conducted individual face - to - face interviews and did the observations with all the teachers. 


\subsection{Identification of children who experience problems}

Teachers are using various methods to identify children who experience problems, but these are not standardised.

The DBE should train teachers to be able to identify such children, based on agreed strategies which would make identification uniform in all schools, and remediation which should follow a standard pattern too.

Teachers who participated in this study among others claimed that they could identify such children when they fail to do well in response to questions in class. As such they did not look into all the reasons leading to failure to respond positively to questions or activities. These teachers themselves are not trained to identify children who experience difficulties (in ) and as such provide a variety of reasons for children's difficulties. Consequently even children who do not experience difficulties might be wrongfully identified as such.

Once these children are identified, remediation should take place promptly by their being enrolled in the proposed programme. In it, the children are to remain until they have mastered the programme or overcome their difficulties before they exit the programme and are replaced by new entrants.

The solution to the LoLT problem is to use English as a medium of instruction. It is difficult to offer mother tongue instruction where there are more than three different languages spoken by children which the teacher sometimes does not even know. For instance, some of the children coming from certain countries north of SA speak French as a first language; none of the teachers know it and would not be able to explain to such children in their own language. Children too would be unable to express themselves. Hence LoLT is a very serious barrier to learning itself.

It is further recommended that children must be taught to deal with numbers first by using concrete objects.

Finally, the FFLC strategy, based on Dowker's programme termed "Numeracy recovery: a pilot scheme for early intervention with young children with numeracy difficulties" is proposed. The rationale for using this programme is that the children whom Dowker mentioned in her programme are similar to the ones I observed during data collection in many respects.

This thesis has demonstrated that children from impoverished socio-economic backgrounds and ethnic minorities are most at risk of educational difficulties and failure (Van Tuijl, Leseman \& Rispens 2001: 148). If not attended to, the difficulties widen over time and eventually lead to lack of self-esteem and finally failure. That is why it is of utmost importance that children who experience mathematical difficulties are identified as soon as possible.

Children go from counting concrete objects and concretely dealing with numbers to counting and dealing with numbers abstractly (Van Luit, 2000). Consequently, work with concrete materials should precede any introduction of symbolic abstractions. Van Luit (2000) states that young children, with special educational needs, benefit from early maths instruction and practice at three levels, namely, manipulating concrete objects, using semi concrete presentations of objects, and performing mental acts. These three levels correspond to the three stages of learning identified by Piaget (1952).

In conclusion to the study, the proposed programme will be based on the Dowker (2001) programme. In the next paragraph the proposed programme will be discussed.

Continued research is needed to investigate intervention for struggling children: intervention that consists of the critical features of instructional design, including sufficient time for children to learn early concepts and operations (Bryant, Bryant, Roberts, Porterfield \& Gersten 2011:9).

\section{Recovery Programme (MRP)}

According to Carr (2004:8), Professor Leslie Steffe and his colleagues at the University of Georgia undertook what they termed the "Recovery Programme" (MRP) in an attempt towards early identification and intervention of children who develop a negative attitude towards. Their research indicates that vast differences in mathematical knowledge already exist among children when they initially enter school.

They also allege that strong negative attitudes to can develop as the children proceed with their studies. The MRP was directed towards early identification and intervention in this connection, and to provide children with a programme for individualised teaching. Children are assessed by means of an "Interview Schedule". The assessment is done orally, seeking to identify among others, counting and place value. Once identified, children with negative attitudes are then given one to one teaching by the class teacher in order to address the child's problems from a constructivist perspective. This is carried out for 10 to 15 weeks for 30 minutes daily, up to four or five times a week. Carr (2004:8-9) described how low-attaining children were identified and raised to a level where they could return and function successfully in the mainstream class at an early stage, and subsequently be provided with intensive, individualised remediation. 


\section{Intervention Strategy at School Level in the South African Context in the Classroom}

As the one person who spends long hours with the children during the day, the teacher knows the children better than the parents do. In the case where a child experiences difficulties, the teacher would use strategies like individual assistance, and modifying the curriculum so that the child can be accommodated. If there is no improvement from the child, then the child is referred to the School Base Support Team (SBST).

Once the child is identified as experiencing difficulties (such as ) the child's profile document will serve primarily as a tool for educators to plan intervention and support on a day-to-day basis as part of the teaching and learning process. The uncovering of difficulties to learning must be based on sound observation, interviews and consultations, previous records, reflection, formative actions and should be grounded in the curriculum (The South African National Strategy on Screening, Identification, Assessment and Support (DoE SIAS), 2008:81). Once the educator has exhausted all strategies and support interventions he or she will consult with the institutional level support teams (ILSTs).

The South African White paper 6 (2000:33) asserts that the ILSTs should be involved centrally in identifying at risk children and addressing difficulties to learning. "Early identification of difficulties to learning will focus on children in the Foundation Phase (Grades R to 3) who may require support, for example through tailoring of the curriculum, assessment and instruction."

The South African National Strategy on Screening, Identification, Assessment and Support (DoE SIAS 2008:78) argues that if there are no ILSTs at a school, the District- based Support Teams (DBST) must assist to set them up.

\subsection{Findings and discussions}

\subsubsection{How do teachers identify children who experience difficulties?}

This question was asked with the aim of finding out what method/s were used by the teachers to identify children who experience problems in learning and to ascertain whether those methods are effective or not.

The teachers claimed that they identified the latter through their (children's) performances in class tasks and tests. They also asserted that they would also identify poor performing pupils by asking oral questions; those not responding would be deemed to be experiencing problems. Report cards from the previous grade (grade two) teacher were said to indicate children with problems. Some children, it is averred, were identifiable by their failure to participate in group discussions.

Teachers were asked how they identified children who experience difficulties. This question was intended to determine whether teachers were able to identify such earners and the methods they use in so doing. Effective identification would result in help being given to such children on the one hand, while on the other hand, lack of identification may result in difficulties not being attended to. The teachers responded as follows:

All participants agreed that children are identified through tests and failure to respond/give feedback. A minority indicated that they used observation books from the previous Grade. Very few said that they could identify children through failure to answer questions orally. A minority said they identified children through mental work and different strategies

Although teachers explained that the intervention they received provided them with better teaching skills there is no certainty that this added significant value to their teaching approach. The problems in the grade 3 programme persisted despite the intervention because the content in the intervention was taught for a day with no follow up the next day to strengthen what the children had learned the previous day. Success in learning was also limited by the sequencing of activities in the intervention programme. This means that a sound intervention programme may well be compromised by a lack of repetition to entrench understanding, poor sequencing and overloading.

\section{Conclusion}

In order to address the problems identified in this study, the following recommendations are made. To address the issue of teaching approaches, it is important that teachers use a variety of teaching methods in order to accommodate all children and also encourage children to use concrete objects.

Children's challenges in computations could be addressed by selecting SBST members who have a background and who are trained to do remedial work.

Most SBSTs do not consist of members who are qualified to act in this capacity. In many schools the SBST is made up of the principal and other members of the SMT who do not necessarily possess expertise in supporting children 
who experience difficulties in but are included in the SBST by virtue of their seniority in the schools. Assistant teachers involved in the SBSTs should consist only of members qualified in the subject. They should also be knowledgeable about supportive measures that can improve children's abilities.

With regard to the identification of children who experience difficulties it became evident that the methods the teachers used could be problematic themselves. For instance teachers who concluded that these children who did not participate during the lesson were encountering challenges could be wrong because such children could be struggling with the language of teaching and not per se. Since no standard criteria are given to teachers for the identification of such children it will be prudent to consider the teachers' expertise in teaching, the child's language and the curriculum content.

Finally, we therefore conclude and recommend that, in order to address the problems identified in this study, the following recommendations are made. To address the issue of teaching approaches, it is important that teachers use a variety of teaching methods in order to accommodate all children and also encourage children to use concrete objects. Children's challenges in computations could be addressed by selecting SBST members who have a background and who are trained to do remedial work. Most SBSTs do not consist of members who are qualified to act in this capacity. In many schools the SBST is made up of the principal and other members of the SMT who do not necessarily possess expertise in supporting children who experience difficulties in but are included in the SBST by virtue of their seniority in the schools. Assistant teachers involved in the SBSTs should consist only of members qualified in the subject. They should also be knowledgeable about supportive measures that can improve children's abilities.

In some schools the School Base Support Team (SBST) exists only in name. An investigation of the team involved, demonstrated that in most schools the type of intervention given to the children does not improve their performance. For example, in most schools Grade 3 children are given Grade 1 work as an intervention. This is only part of the solution to the problem as the intervention leaves out the Grade 2 work. The child therefore would continue to have this gap (Grade 2 work) unfilled in his or her development and numerical understanding.

\section{References}

Bryant, D. P., Roberts, G., Bryant, B. R., and DiAndreth- Elkins, L. (2011). Tier 2 for K - 2 early numeracy number sense interventions for kindergarten and first - grade students with difficulties. In Gersten and B. Newman - Gonchar (Eds), Rtl book (pp 65 - 83). Baltimore, MD: Brookes.

Carr, J. (2004). in the primary schools: discussion document circulated for the Irish National Teachers Organisation (INTO) Consultative Conference of Education.

Corbin, J. \& Strauss, A. (2008). Basics to qualitative research $3^{\text {rd }}$ (Ed) USA: Library of Congress Cataloguing- in- Publication Data.

Croark, C.J, Mehaffie, K.E, McCall, R.B \& Greenberg, M.T. (2007). Evidence-Based Practices and Programs for early childhood. United Kingdom: Sage.

Department of Basic Education, January 4 (2012). Big decline in numbers of matric maths passes - Equal Education. Pretoria: Department of Education.

Department of Education. National Strategy on Screening, Identification, Assessment and Support 14 March 2008. Pretoria: Department of Education

Department of Education. (2001). Education White Paper 6, 30 July 2001. Special Needs Education Building and Inclusive Education and Training System. Pretoria: Department of Education.

Dowker, A.D. (2001). Numeracy recovery: a pilot scheme for early intervention with young children with numeracy difficulties. Vol. 16, No 1, 6-10.

Guerin, G. \& Male, M.C. (2006). Addressing learning disabilities and difficulties. United Kingdom: Library of Congress Cataloguing- inPublication Data.

Joiner, L.M. (1978). Identifying child's with special needs: A practical guide to developmental screening. Florida: Learning Publications, Inc.

Piaget, J. 1952. The origins of intelligence in children. pp 1-20. New York: WW Norton \& Co.

Pierangelo, R. (1994). A survival kit for the Special Education Teacher. United States: Library of Congress Cataloguing- in- Publication Data.

Steele, M.M. (2004) Early Childhood Education Journal, 32(2), 75-76.

Stobie, I., Boyle, J., Woolfson, L., Truswell, E., \& Connaughton, N. (2004). Quality indicators for effective early intervention in literacy and numeracy. International Journal of Early Years Education, 12(2),.

Van Luit, J. E. H., \& Schopman, E. A. M. (2000). Improving early numeracy of young children with special educational needs. Remedial and Special Education 21(1), 27-40. [Online] Available: ProQuest Educational Journals [2004, September 20].

White, C.J. (2005). Research: a practical guide. Pretoria. Ithuthuko Investment (Publishing). 